Dro 383

UCRL-51447

\title{
MECHANICAL PROPERTIES OF NUGGET SANDSTONE
}

\author{
R. N. Schock \\ A. E. Abey \\ B. P. Bonner \\ A. Duba \\ H. C. Heard
}

August 28, 1973

Prepared for U.S. Atomic Energy Commission under contract Nc. W-7405-Eng-48

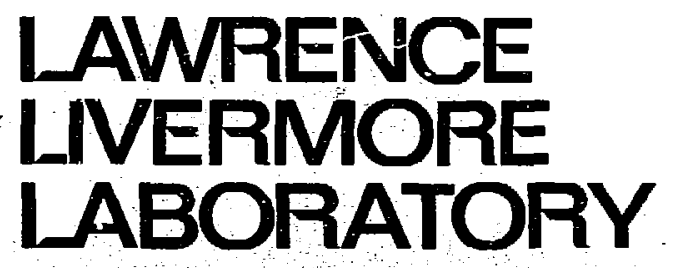

University of California / Livermore 
NOTict

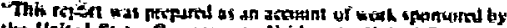

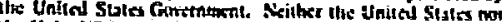

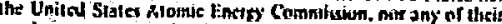

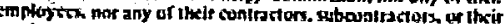

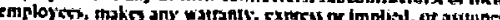

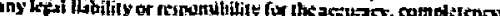
or tikefult the of any informatlan.

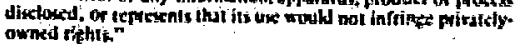

\section{Printed in the United States of Anterica} Available from

National Technical Information Service

U.S. Department of Commerse 5285 Port Royal Road Springfield, Virginia 22151

Price Printed Copy $\$$ \% Microfiche $\$ 0.95$

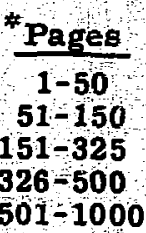

NTIS Selling Price

$\$ 4.00$

$\$ 5.45$

$\$ 7.60$

$\$ 10.60$

$\$ 13: 60$ 
TID-4500, UC- 11

Environmental and Earth Sclences

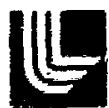

LAMPINCE LNEFMORE LARORATOAN

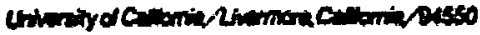

UCRL-51447

\section{MECHANICAL PROPERTIES OF NUGGET SANDSTONE}

R. N. Schock

A. E. Abey

B. P. Bonner

A. Duba

H. C. Heard

MS. date: August 28, 1973

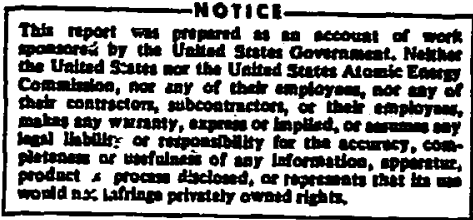




\section{Contents}

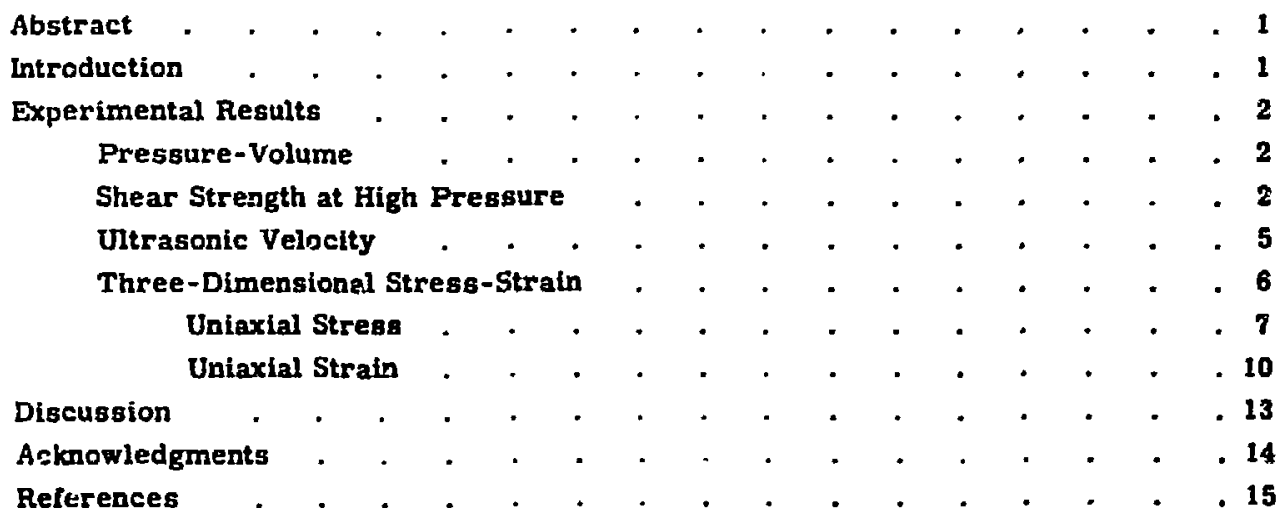




\title{
MECHANICAL PROPERTIES OF NUGGET SANDSTONE
}

\begin{abstract}
The mechanical properties of Nugget sandstone have been determined from a number of independent measurements at pressures up to 30 kbar. Pressurevolume, strength, uniaxial stress, and uniaxial strain tests yield the failure surface and effective moduli as a function of gtress state, i.e., mean pressure and shear stress. Acoustic velocity daterminations provide the effective moduli for low amplitude dynamic waves. At atmospheric pressure the initial effective bulk modulus in tegts with applied differential stresses ( $\sim 40$ kbar) differs from tha) determined hydrostatically (23 kbar). This

and a large pressure derivative of the shear modulus at low pressure are believed to be due to an abundance of cracks with low aspect ratioe.

The initial effective shear modulus of about $\mathbf{5 5}$ koar increasles rapidly with the closing of cracks. At 1 kbar confining pressure, a shear moilulus of about $120 \mathrm{kbar}$ is determined in both uniaxial stress and uniaxial strain experiments The rock has an ultimate strength comparable to granite ( $1.2 \mathrm{kbar}$ unconfin=d) and exhibits brittle behavior at failure to the highest mean pressurs studied (14 kbar). Failure is preceded by dilatant behavio. .
\end{abstract}

\section{Introduction}

As part of a Laboratory program (Seismic Evasion) dea!ing with the detecticn of underground nuclear explosions, we have measured the physical propertíes of various materials selected to represent a wide range of possible responses to stress pulses. The physical properties so determined are then uged in conjunction with small-scale explosion and shock-wave measurements to define the behavior of the material over a wide range of stresses, strains and strain rates. This information is then used to develop numerical techniques which seek to model stresswave propagation. Factors such as water content and porosity, and related physical properties such as moduli and strength, are well known to have a large effict on stress-wave propagation.

In this report we present the result of high-pressure, mechanical properties measurements on one material, the Nugget sandstone, from Utah. This sandstone is composed primarily of detrital quartz with siliceous cementing materiala. Based on a reported quartz content of $99 \%$; the rock may be classified as orthoquartzite ${ }^{2}$ or a quartz arenite by the more recent scheme of Pettijohn et al. ${ }^{3}$ The average density of the material used in this study is

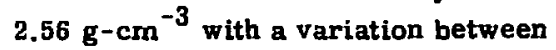


$2.54 \mathrm{~g}^{-\mathrm{cm}^{-3}}$ and $2.57 \mathrm{~g}-\mathrm{cm}^{-3}$. Most samples, however, varied by no more than $0.006 \mathrm{~g}^{-\mathrm{cm}^{-3}}$ from this average. All samples were fabricated with the cylindrical axis perpendicular to the poorlydefined bedding. No attempt was made to determine the degree of anisotropy.

We have determined the pressurevolume loading behavior to $30 \mathrm{kbar}$, the failure envelope to 14-kbar mean pressure, and acoustic velocities to $10 \mathrm{kbar}$. In additior, the three-dimersional stressstrain relationsbips in quasistatic lo-ding have been measured to 13 kbar to deter mine such parameters as the stress and path dependence of the shear modulus ard to compare static loading zoduli with those determined dynamically. The experimental techniques used have been described in detail elsewhere. ${ }^{4-8}$ All stiesses are referred to a Cartesian coordinate system with $\sigma_{1}, \sigma_{2}$ and $\sigma_{3}$ the maximum, intermediate, and minimum principal stresses, reapectively. In all cases reported here, with the exception of the indirect iensile (Brazil) tests, $\sigma_{2}$ and $\sigma_{3}$ are equai. Stress is taken as positive and strain as negative in compression, All of our measureznents are at strain rates in the range of $10^{-4}$ to $10^{-5} \mathrm{gec}^{-1}$, at room temperature, anci on dry sandstone.

\section{Experimental Results}

\section{PRESSURE-VOLUME}

We measured the pressure-volume relationship for Nugget sandstone on six teat samples. Two samples were tested to $30 \mathrm{kbar}$ in a quasihydrostatic pistoncylinder tevice. These samplea were $2.2 \mathrm{~cm}$ in diameter by $2.5 \mathrm{~cm}$ long. Tin was used as the pressure medium. The remaining four samples were tested to 14 kbar in a hydrostatic piston-cylinder apparatus using oil as the pressure fluid. Two of the samples tested to 14 kbar were $1.9 \mathrm{~cm}$ in diameter by $2.5 \mathrm{~cm}$ long and another two were $3.1 \mathrm{~cm}$ in diameter by $5 \mathrm{~cm}$ long. The composite pressurevolume relationship from the six samples tested is shown in Fig. 1. In drawing this composite curve, the hydrostatic data were used at the low pressures (< 3 kbar). The data from ali eix runs agree to within $0.5 \%$ for $\mathrm{V} / \mathrm{V}_{0}$ in the 3 to 14 -kbar region.
Over the common pressure range of 3 to $14 \mathrm{kbar}$, the bulk modulus determined by both methods agreed very well $( \pm 5 \%$ of the stated value).

The composite curve shows $\mathrm{V} / \mathrm{V}_{0}$ to be a mazotonic decreasing function over the presgure range to $30 \mathrm{kbar}$, except for the region around 8 sbar where a slight " $S$ " shape is seen in the pressure-volume curve. This is so slight that for most purposes the bulk modulus can be considereci as a monotonic Increasing function of the pressiure, as shown in Fig. 2 . Table 1 lists the values of the bilk modulus at verfous pressures.

\section{SEIFAR STRENGTH AT HIGH PRESSURE}

Jackete $J$ cylinders $(2 \mathrm{~cm}$ diam by $4 \mathrm{~cm}$ ) were used to determine the strength of the dry Nugget sandstone at confining pressures ranging to $7.0 \mathrm{kbar}$. Initial 


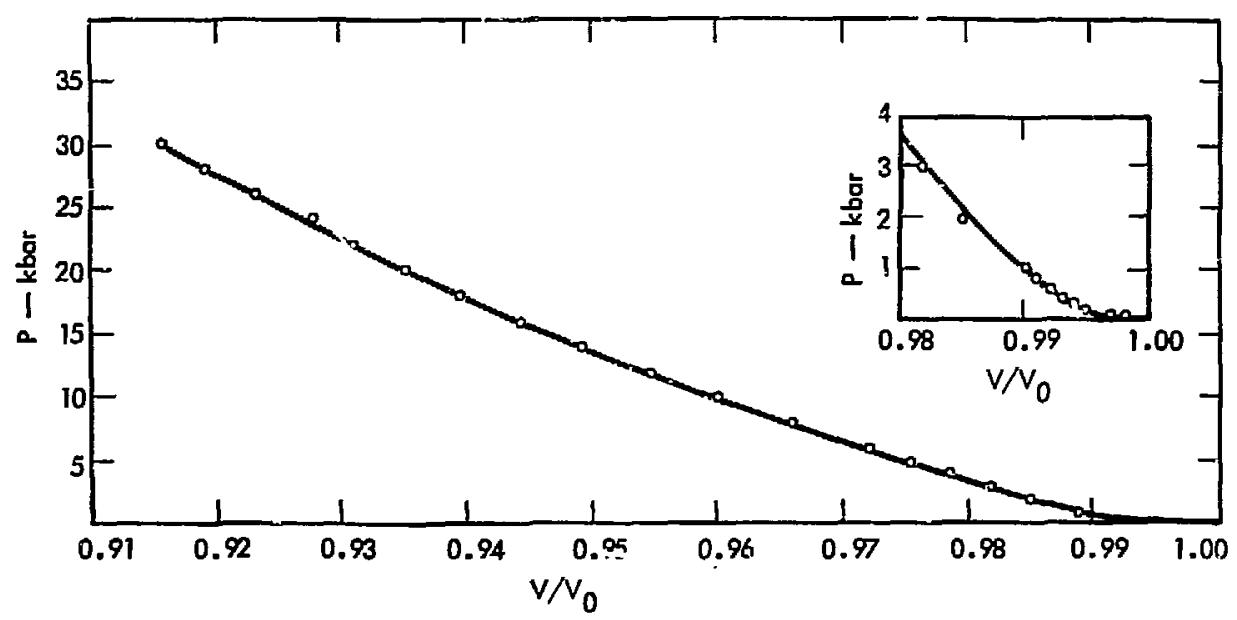

Fig. 1. Pressure-voluzie relationship for Nugge sandstone.

measurements weretaken in the form of axial force-axial displacement traces and were reduced to yield differential stressaxiai strain curves. Inspection of these

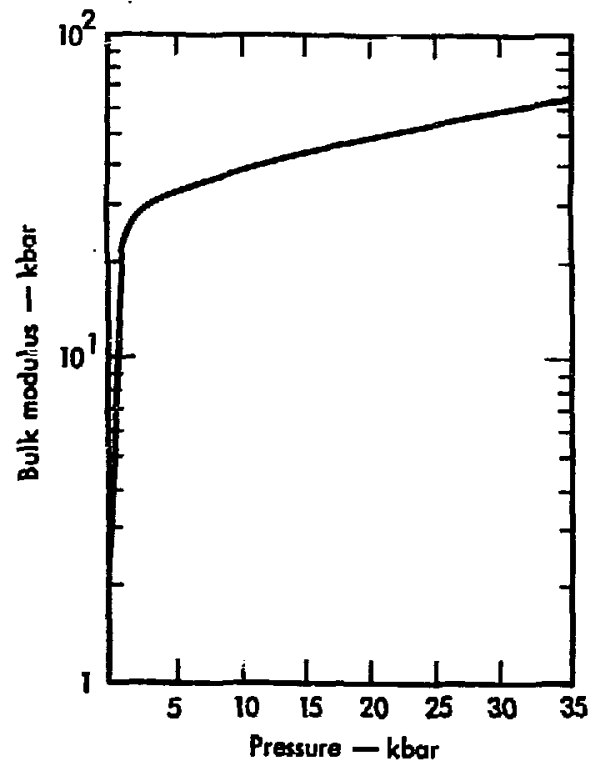

Fig. 2. Bulk modulus as a function of presgure for Nugget sandetone. curs is, together with the condition of the test sample after deformation, indicated that most, if not all of the inelastic strain had occurred by brittle fracture. Usually conjugate but occasionally single shear fracture planes, inclined $\sim 30^{\circ}$ to $\sigma_{1}$, were obvious; cohesiovi across the naxrow dislocation zones was usually lost. In addition, tensile fracture planes orienied parallel to $\sigma_{1}$ were commoniy noted.

Table 1. Derived bulk modidi (K), Nugget sandstone.

\begin{tabular}{cc}
\hline $\mathbf{P}$ (kbar) & Nugget Sandstone \\
\hline 0 & K (kbar) \\
\hline 0.5 & 23 \\
1 & 80 \\
3 & 219 \\
5 & 290 \\
10 & $32)$ \\
15 & 375 \\
20 & 430 \\
25 & 475 \\
30 & 517 \\
\hline
\end{tabular}


The ultimate (maximum) strength from these tests can be used to define a surface in shear-stress mean-pressure space.

Figure 3 shows this surface or failure

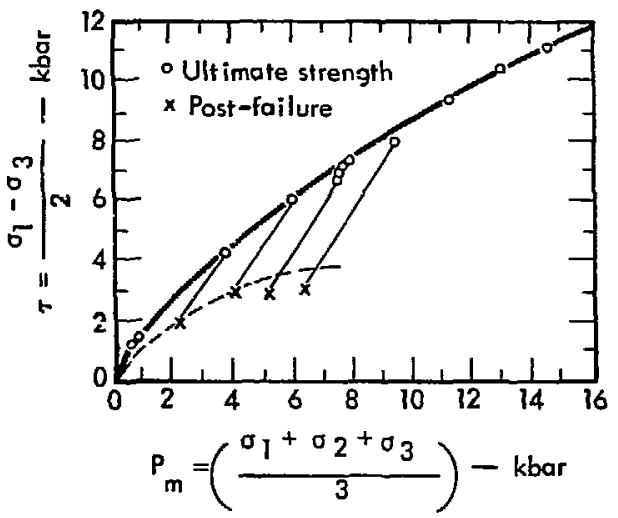

Fig. 3. Failure envelope, Nugget sandstone. envelope along with the individual data points from each test. Table 2 summarizes the principal stresses at failure for all tests. As is usually observed in most brittle rock materials, after the initial rupture at the ultimate stress difference, the axial stress does not drop immediately to the value of the confining pressure. Instead, the fractured rock supports approximately one-half the maximum stress difference and further deformation occurs by stick-slip sliding between the rupture surfaces. As is observed in most rocks, ${ }^{9}$ post-failure shear strengths in Nugget sandstone remain at one-third to twothirds of the maximum value until the jacket ruptures. Failure in the weak tygon jacket at the initial fracture prevented measurement of this phenomenon above

Table 2. Summary of uniaxial-compression and Brazil-test data, Nugget sandstone.

\begin{tabular}{|c|c|c|c|c|c|c|c|c|c|}
\hline Test type & $\begin{array}{c}\sigma_{1} \\
\text { (kbar) } \\
\end{array}$ & $\begin{array}{c}\sigma_{1}{ }^{\prime} \\
\text { (kbar) }\end{array}$ & $\begin{array}{c}\sigma_{3} \\
\text { (kbar) }\end{array}$ & $\begin{array}{c}\sigma_{3}^{\prime} \\
(\mathrm{kbar}) \\
\end{array}$ & $\begin{array}{c}\tau \\
(\mathrm{kbar}) \\
\end{array}$ & $\begin{array}{c}\tau^{\prime} \\
\text { (kbar) }\end{array}$ & $\begin{array}{c}\mathrm{P}_{\mathrm{m}} \\
\text { (kbar) }\end{array}$ & $\begin{array}{c}P_{m}{ }^{\prime} \\
\text { (kbar) }\end{array}$ & Behavior \\
\hline \multirow[t]{4}{*}{ Brazil } & 0.26 & & -0.09 & & 0.17 & & 0.06 & & Brittle \\
\hline & 0.33 & & -0.11 & & 0.22 & & 0.07 & & Brittle \\
\hline & 0.35 & & -0.12 & & 0.23 & & 0.08 & & Brittle \\
\hline & 0.45 & & -0.15 & & 0.30 & & 0.10 & & Brittle \\
\hline \multirow[t]{13}{*}{ Uniaxial comp. } & 2.30 & & 0.001 & & 1.15 & & 0.77 & & Brittle \\
\hline & 2.60 & & 0.001 & & 1.30 & & 0.87 & & Brittle \\
\hline & 9.60 & 4.76 & 1.00 & 1.06 & 4.30 & 1.85 & 3.87 & 2.25 & Brittle \\
\hline & 14.13 & 8.52 & 2.03 & 2.15 & 6.05 & 3.19 & 6.06 & 4.27 & Brittle \\
\hline & 17.52 & 9.44 & 3.01 & 3.19 & 7.26 & 3.13 & 7.85 & 5.27 & Brittle \\
\hline & 16.95 & & 3.00 & & 6.98 & & 7.65 & & Brittle ${ }^{a}$ \\
\hline & 16.78 & & 3.00 & & 6.89 & & 7.59 & & Brittle $e^{a}$ \\
\hline & 17.50 & & 3.00 & & 7.25 & & 7.83 & & Brittle \\
\hline & 17.24 & & 3.00 & & 7.12 & & 7.75 & & Brittle \\
\hline & 20.04 & 11.12 & 4.02 & 4.29 & 8.01 & 3.42 & 9.36 & 6.57 & Brittle \\
\hline & 23.77 & 5.52 & 5.02 & 5.52 & 9.38 & 0 & 11.27 & 5.52 & Brittle \\
\hline & 26.93 & 6.68 & 6.07 & 6.68 & 10.43 & 0 & 13.02 & 6.68 & Brittle \\
\hline & 29.51 & 7.33 & 7.01 & 7.35 & 11.25 & 0 & 14.51 & 7.33 & Brittle \\
\hline
\end{tabular}

$20.025-\mathrm{cm}$ lead jacket. 
11.2 kbar mean pressure. Both the ultimate strength and the post-failure data are quite reproducible, and each has a rather narrow scatter band. Jacketing by either tygon, lead, or copper, gave identical results.

Overall, this sandstone appears to be quite brittle and strong, at least when compared to graywacke sandstones measured in this Lajoratory. ${ }^{10}$ The brittleductile transition for the Nugget sandstone must be in excess of 15-kbar mean pressure - at least a factor of two higher than for sandstones from the Wagon Wheel site. ${ }^{11}$ The slope of the shear-stress meanpressure envelopes (unfractured) is nearly identical (0.65) for these two sandstones. Shear strengths in the Nugget sandstone are about $10 \%$ higher, due probably to a higher initial cohesive strength and better cementation between grains and lower initial porosity.

Tensile strengths were also determined by a series of Brazil tests. The relatively high values of $90-150$ bars (Table 2), are characteristic of a well-cemented aggregate. Tensile strengths in quartz-rich aggregates may vary frcm zero (sand pile) to at least 250 bars for a pell cemented orthoquartzite. ${ }^{12}$ The average tensile atrengths for Nugget are siightly higher than for the Wagon Wheel sandstone ${ }^{11}$; 120 versus 110 bars.

\section{ULTRASONIC VELOCITY}

Travel-times of both shear and compressional pulses through small cylindrical specimens $(1.9 \mathrm{~cm}$ diam by $\sim 2.5 \mathrm{~cm}$ long) were determined to $10 \mathrm{kbar}$ at $1 \mathrm{MHz}$, using polycrystalline ceramic $\mathrm{Pb}(\mathrm{Zr}, \mathrm{Ti}) \mathrm{O}_{3}$ transducers. ${ }^{13}$ The data are plotted in
Fig. 4 as a function of pressure. Table 3 contains velocities and calculated moduli. We used Cook's method ${ }^{14}$ to estimate the change in specimen length. This method employs a step-wise integration of the calculated bulk modulus, described in detail by Schock et aㅡ. ${ }^{13}$

Both velocities are observed to increase rapidly with pressure as the effective deformation moduli increase for these low-amplitude ultrasonic waves. This behavior is characteristic of many common rock types, 15 and is usually associated with microcracks having low-aspect ratios that close easily with pressure. There is little indication of the inelastic compaction which is very evident in more porous sandstones. ${ }^{16}$ Although most of the velocity change has occurred at $2 \mathrm{kbar}$, both velocities are still increasing slowly at the highest pressures obtained. This is in contrast to crystalline igneous rocks (Westerly granite) where the velocities do not increase significantly above 2 kbar because the voids are primarily long, narrow microcracks which are easily closed with pressure. ${ }^{13}$ Apparently a small amount of porosity remains at $10 \mathrm{kbar}$ in the Nugget sandstone, which is probably more spherical, and thus is resisting collapse. Such behavior has been observed in another quartz-rich rock, the Stirling quartzite. ${ }^{17}$ The shear modulus exceeds the bulk modulus at ambient pressure, in agreement with the static results which follow. This behavior reverses at $\sim 200$ bars, and has been correlated with interlocking textures in sedimentary rock. ${ }^{10}$

The moduli calculated from the traveltimes of small-amplitude waves are considerably greater than those measured 


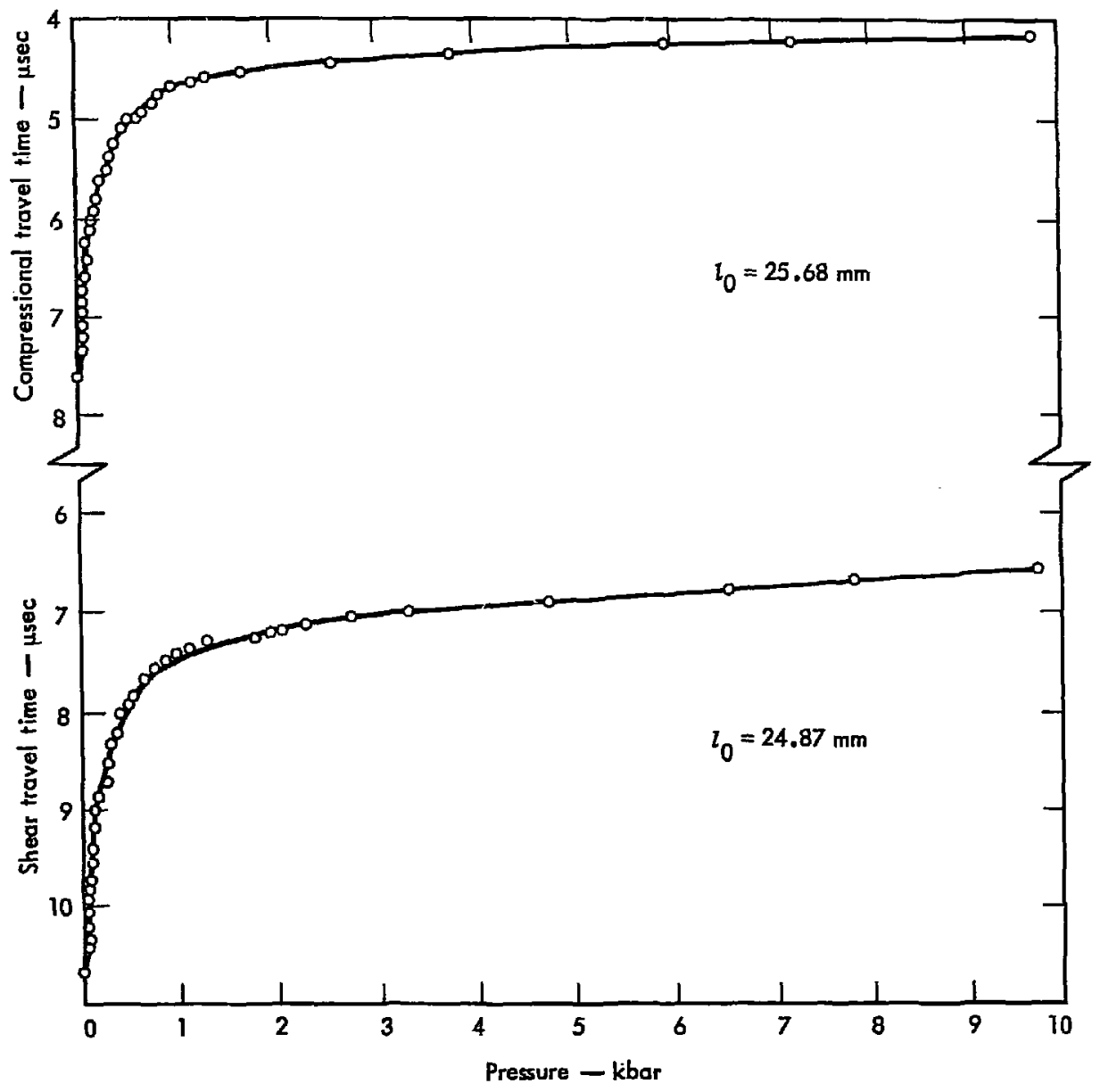

Fig. 4. Measured travel-times for small-amplitude strain waves as a function of hydrostatic pressure for Nugget sandstone.

during the static experiments (compare Tables 1 and 3 , and the uniaxial stress and uniaxial strain results). This discrepancy is typical of porous rock, particularly those containing long narrow cracks. ${ }^{18}$ Rock moduli are usually strong functions of stress amplitude and strain rate. This, together with the effect of wave-scattering around arrays of micro- cracks, offers alternative explanations of these differences in moduli.

\section{THREE-DIMENSIONAL} STRESS-STRAIN

The three-dimensional stress-strain relationship was measured over a variety of loading paths in shear stress and mean stress space, using jacketed cylindrical 
Table 3. Calculated velocities and moduli for Nugget sandstone, perpendicular to the bedding.

\begin{tabular}{cccccccc}
\hline $\begin{array}{c}\text { Pressure } \\
\text { (kbar) }\end{array}$ & $\begin{array}{c}\rho \\
\left(\mathrm{g} / \mathrm{cm}^{3}\right)\end{array}$ & $\begin{array}{c}\mathrm{V}_{\mathrm{p}} \\
(\mathrm{km} / \mathrm{sec})\end{array}$ & $\begin{array}{c}\mathrm{V}_{\mathrm{s}} \\
(\mathrm{km} / \mathrm{gec})\end{array}$ & $\begin{array}{c}\mathrm{K} \\
(\mathrm{Mbar})\end{array}$ & $\begin{array}{c}\mu \\
(\mathrm{Mbar})\end{array}$ & $\begin{array}{c}\text { Poisson's } \\
\text { ratio }\end{array}$ & $\begin{array}{c}\text { Young's modulus } \\
(\mathrm{Mbar})\end{array}$ \\
\hline 0 & 2.560 & 3.44 & 2.34 & 0.117 & 0.140 & 0.07 & 0.300 \\
0.1 & 2.562 & 4.14 & 2.73 & 0.184 & 0.191 & 0.11 & 0.426 \\
0.2 & 2.563 & 4.46 & 2.89 & 0.224 & 0.215 & 0.14 & 0.488 \\
0.4 & 2.565 & 4.92 & 3.08 & $0.29 ?$ & 0.244 & 0.18 & 0.574 \\
0.6 & 2.567 & 5.16 & 3.18 & 0.337 & 0.260 & 0.19 & 0.620 \\
0.8 & 2.568 & 5.30 & 3.25 & 0.358 & 0.272 & 0.20 & 0.651 \\
1.0 & 2.570 & 5.45 & 3.41 & 0.366 & 0.299 & 0.18 & 0.705 \\
2.0 & 2.576 & 5.71 & 3.45 & 0.429 & 0.307 & 0.21 & 0.744 \\
3.0 & 2.582 & 5.82 & 3.52 & 0.448 & 0.319 & 0.21 & 0.774 \\
4.0 & 2.588 & 5.91 & 3.54 & 0.470 & 0.325 & 0.22 & 0.792 \\
5.0 & 2.593 & 5.99 & 3.59 & 0.485 & 0.333 & 0.22 & 0.813 \\
6.0 & 2.599 & 6.05 & 3.62 & 0.499 & 0.340 & 0.22 & 0.831 \\
7.0 & 2.604 & 6.08 & 3.64 & 0.503 & 0.344 & 0.22 & 0.841 \\
8.0 & 2.609 & 6.12 & 3.67 & 0.508 & 0.352 & 0.22 & 0.857 \\
9.0 & 2.614 & 6.14 & 3.69 & 0.512 & 0.356 & 0.22 & 0.867 \\
10.0 & 2.619 & 6.15 & 3.72 & 0.509 & 0.362 & 0.21 & 0.878 \\
\hline
\end{tabular}

samples. For work at axial stregses above $5 \mathrm{kbar}$, the samples (2-cm-diam $\times 3 \mathrm{~cm}$ ) were loaded with the piston of a piston-cylinder pressure vessel in which the confining pressure could be controlled independent of the advance of the piston. In this case, the samples were jacketed with either $0.012-\mathrm{cm}$-thick or $0.025-\mathrm{cm}$ thick lead, and strain gages were bonded to the jacket. For work at low axial stresses at confining pressures to 4 kbar, a fluid loading system was used and the samples $(2.5-\mathrm{cm}$-diam $\times 6 \mathrm{~cm})$ were jacketed with a thin film of epoxy. ${ }^{8}$ Straingage output was corrected for the effect of pressure. ${ }^{19}$

\section{Uniaxial Stress}

Samples were loaded to failure in uniaxial stress at confining pressures to 5 kbar. Figure 5 shows the measured axial and circumferential strains on loading to fallure at atmospheric confining pressure. In contrast to the circumferential strain, the initial increase in axial

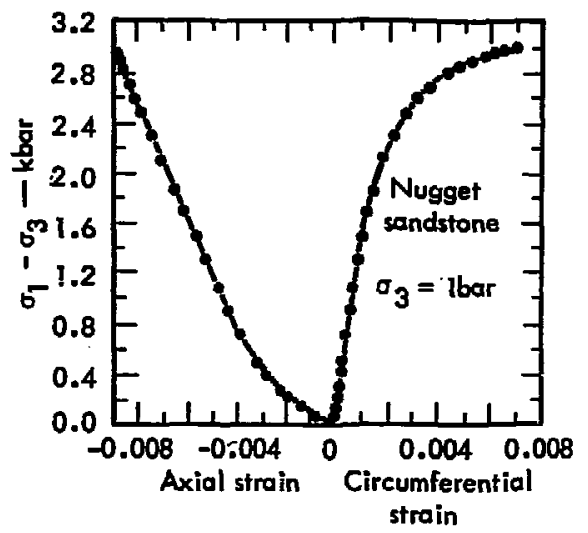

Fig. 5. Axial and circumferential strain as a function of axial stress difference at atmospheric confining pressure. 
strain is nonilinear. Simllar results are well known in granitic rocks, 20,21 and have been attributed to the influence of cracks with low-aspect ratios. In response to an applied axial stress, those cracks whose major axes lie in or nearly in the plane normal to the applied stress offer little resistance and are closed at low stresses. In coutrast, those cracks whose major axes are parallel to $\sigma_{1}$ cannot be closed by this stress. Furthermore they cannot be opened at Ц०พ stresses. The results of these interactions is an increage in axial strain larger than that for the rock without cracks during the first several hundred bars of axial compression. After the cracks are closed, the continued strain response is essentially that of the rock without craciss until higher stress levels where microfracturing is initiated. Thus, one may conclude from the data in Fig. 5 below 1 kbar that the Nugget sandstone contains abundant cracks with low aspect ratios.

As the axial stress is increased to failure, the circumferential strain now begins to increase in a nonlinear fashion while the axial strain increase is nearly linear. This behavicr corresponds to an increase in the macros spic volume of the ro: $i$ (Fig. 6). The volume increase before failure (dilatancy) is well known in brittle rocks 22 and is thought to be the effect of microfractiring ${ }^{23}$ which precedes ultimate failure. Since the predominant strain is circumferential, the microfracturing must be the result of the opening of cracks whose major axes are nearly parallel to $\sigma_{1}$. In Fig. 7 we show the shear strain with increasing axialstress difference. The initial shear modulus $(-1 / 2$ slope in Fig. 7) is found to be 54 kbar. After the cracks are closed, the shear modulus has increased to 155 kbar. This represents the shear modulus of the rock without the influence of cracks. As the rock dilates the shear modulus decreases, gradually approaching zero as the rock breaks. The initial bulk

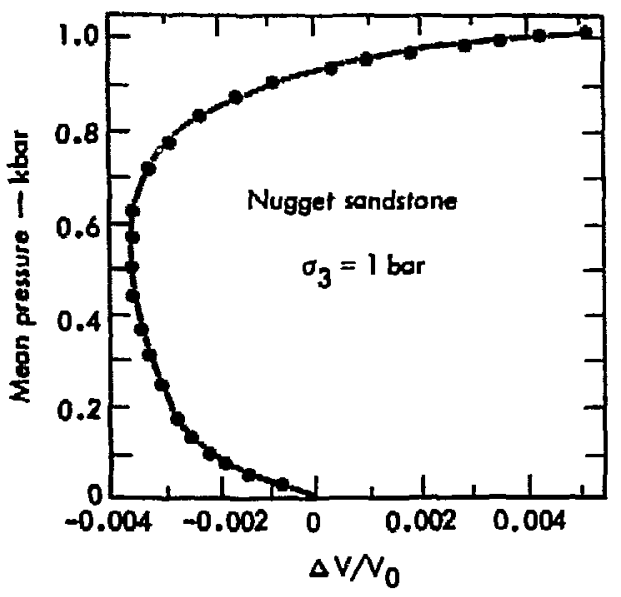

Fig. 6. Volume strain as a function of mean pressure on uniaxial stress loading at atmospheric confining pressure (data from Fig. 5).

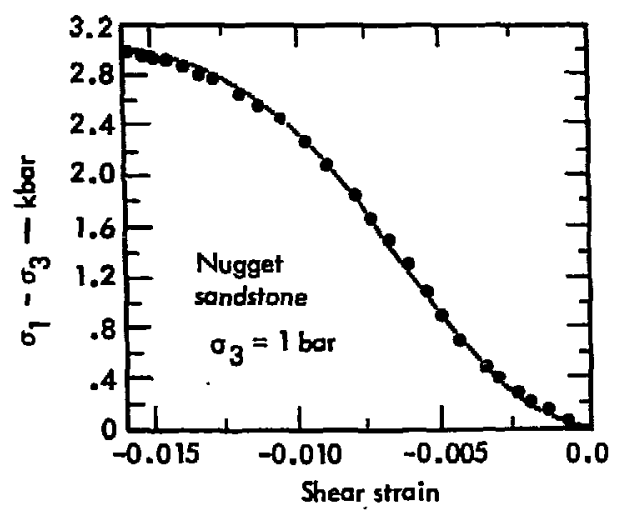

Fig. 7. Shear strain as a function of axial stress difference at atmospheric confining pressure (data from Fig. 5). 
modulus, determined from the data in Fig. 6, is 35 kbar which is lower than the initial effective shear modulus. This is characteristic of sandstones with appreciable detrital quartz contents, ${ }^{10}$ and may be due to the interlocking nature of the grains themselves. An interlocking texture wauld serve to inhibit sliding of grains while not affecting compaction. 7

If we examine the data obtained in a uniaxial stress test at 1-kbar confining pressure we see that compaction of cracks oriented primarily normal to $\sigma_{1}$ is responsible for the nonlinear behavior At 1 kbar the confining pressure itself is enough to close these cracks, and thus a plot of axial strain (Fig. 8) does not show the initial nonlinearity noted in the same test at 1-bar confining pressure. The shear otrain (Fig. 9) also show s no evidence of the infuence of cracks at low $\sigma_{1}$. At high $\sigma_{1}$, the rock still dilates before failure (Fig. 10).

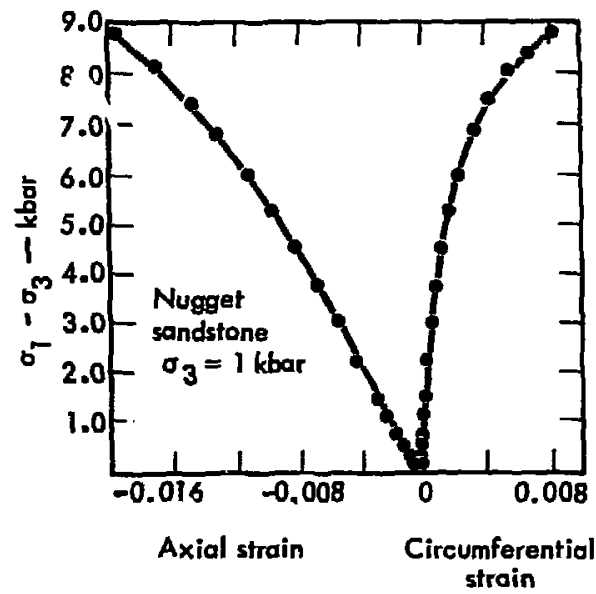

Fig. B. Axial and circumferential strain as a function of axial stress dieference at 1 -kbar confining pressure.
The initial shear modulus at $1 \mathrm{kbar}$ is 223 kbar, well above the initial value at 1 bar and higher than the value obtained at I bar after the axial stress-strain curve became linear. This is due to the increased confining pressure which causes

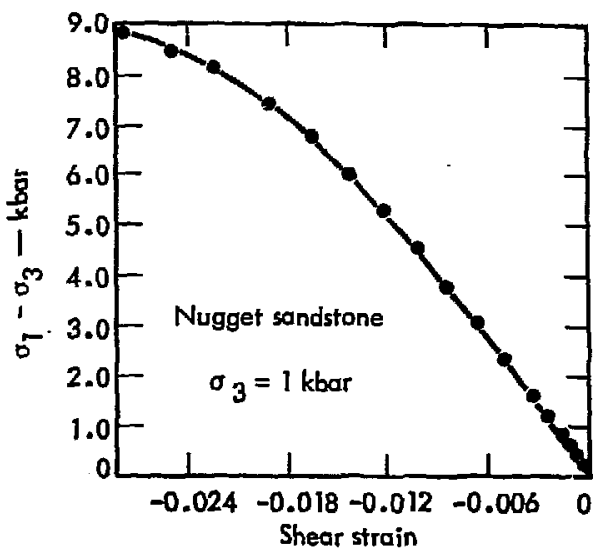

Fig. 9. Shear strain as a function of axial stress difference at 1-kbar confining pressure.

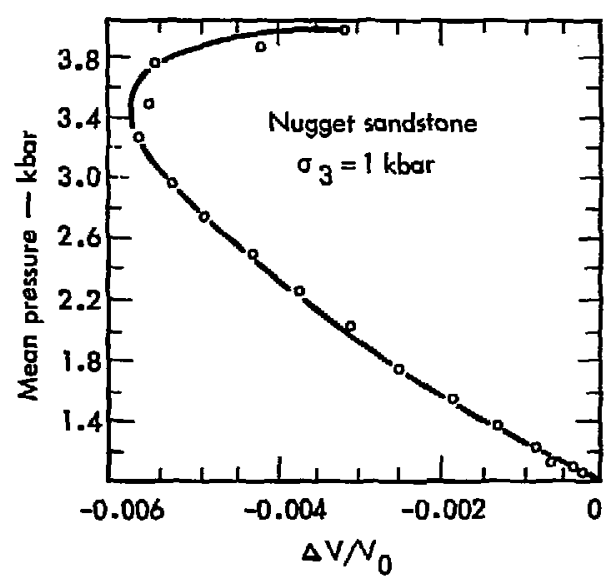

Fig. 10. Volume strain as a function of mean pressure on uniaxial stress loading at 1-kbar confining pressure. 
increased friction between constituent grains and cement. The initial bulk modulus at $1 \mathrm{kbar}$ is $280 \mathrm{kbar}$, higher than that determined under hydrostatic conditions. This surprising behavior persists up to 5 kbar which is the limit of the uniaxial stress tests performed here and is probably due to the influence of cracks, as discussed below.

The behavior of this rock in uniaxial stress is remarkably similar to that of granitic rocks. All of the features just noted as being due to the closing of cracks and the dilatant behavior are found in granitic-type rocks. 7,20 However, both the shear and bulk moduli are lower than those for granites, a feature characteristic of quartzitic sandstones. 7

A typical granite shows a smaller amount of compression in the axial direction due to the closing of cracks. The Hoggar granite ${ }^{20}$ exhibits $<0.05 \%$ strain due to the initial nonlinear portion of its stress-strain curve, in comparison to the $0.2 \%$ shown by the Nugget sandstone in Fig. 5. Nevertheless, this sandstone is somewhat stronger than most granites studied in this Laboratory. 20

No evidence of a decrease in dilatant behavior is observed to 5-kbar confining pressure. This is in agreement with the lack of any evidence of ductile behavior in the failure response. ${ }^{7}$

\section{Uniaxial Strain}

The uniaxial strain test is accomplished by varying the confining pressure as axial stress is increased. Uniaxial strain is assumed to be the condition under which deformation by a plane-shock wave takes place. The condition arises primarily due to restrictions of symmetry, ne- glecting boundary effects. In principle, the high strain rates involved in the shock-wave experiments reduce the possibility of boundary sffects through inertial considerations. During the passage of a plane shock wave no strain normal to the propagation direction occurs, and the pressure surrounding the sample will increase with the axial atress according to the effective moduli of the material, viz.

$$
\frac{\sigma_{1}}{\sigma_{3}}=\frac{3 K+4 \mu}{3 K-2 \mu},
$$

where $\mathrm{K}$ is the effective bulk modulus and $\mu$ the effective shear modulus. The uniaxial gtrain test therefore accomplishes the same result, but at a much lower strain rate.

Figure 11 shows the loading path in uniaxial strain to 7-kbar confining pressure compared to the failure envelope (Fig. 3). Several unloading paths in uniaxial strain are also shown. The loading path, after having started in the direction of the failure surface, begins to curve toward higher confining pressures and seems to parallel the failure envelope. In a recent report ${ }^{24}$ it was shown that in granites the uniaxial strain loading path coincides with the lower limit of the region which describes dilatant behavior. This is because the onset of dilatant behavior is path-independent, and the nonlinear increase in circumferential strain (which is a necessary feature of dilatant behavior) is precluded by definition in a uniaxial strain tegt. In Fig. 11 we have plotted three points at which the Nugget sandstone dilates on loading in uniaxial stress. 


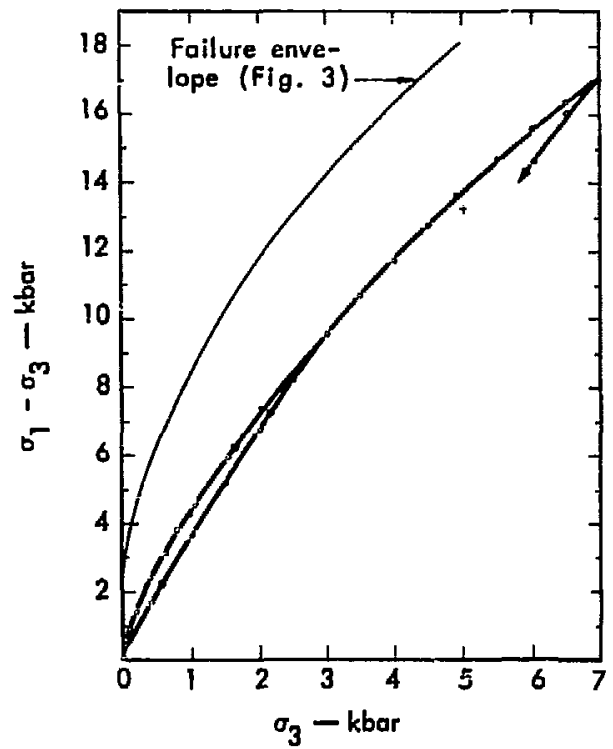

Fig. 11. Axial differential stress as a function of confining pressure for loading in uniaxial strain and on unloading from several pressures. (t) represents the onset of dilatant behavior in a uniaxial stress test.

The onset of dilatancy is defined here as the point at which the mean pressurevolume strain curve in uniaxial stress loading becomes significantly steeper than the hydrostat at corresponding mean pressures. In other words, the bulk modulus becomes greater. (Compare Figs. 6 and 9 with Fig. 1.) These points (Fig. 11) support the hypothesis that the low strain rate uniaxial strain loading curve is controlled by the onset of dilatant behavior. However, available evidence ${ }^{24}$ indicates that under shockloading conditions dilatant behavior may take place although at higher stress levels due to effects of strain rate on crack propagation. Since the failure envelope shown in Figs. 3 and 11 is comparable to that found for three granitic rocks, ${ }^{20}$ we can anticipate a Hugoniot-elastic-limit (HEL) for this rock at stress levels of at least 40-50 kbar. The exact value will be influenced by the strain-rate dependence of failure and inelastic processes which occur before failure. HEL values for polycrystalline quartz aggregates range from 40-97 kbar in the case of pure material and from 40-59 kbar for coarsegrained natural aggregates. ${ }^{25}$ With the extremely high quartz content of this sandstone, one may expect the HEL to be in the 40- to 60-kbar range. Since there is no evidence of compaction in these rocks, as in other sandstones, 7,9 we do not anticipate a relaxation at stresses below those associated with brittle failure.

In Fig. 12 we show the strain measured during uniaxial strain loading. Both the axial stress and the mean pressure are shown for comparison. Also shown are six points determined by Larson ${ }^{26}$ in a series of low-pressure gas gun experiments. In general, these points agree well with the static uniaxial-strain data. There is a tendency toward steeper loading in the static results which might be attributed to strain rate. However, processee which involve compaction, crack propagation, or other inelastic processes are generally strain-rate-dependent in the opposite sense, i.e., they show less compaction at higher strain rates. We have no explanation for this discrepancy.

The initial slope $\left(\sigma_{1}\right.$ versus $\left.\Delta V / V_{0}\right)$ in Fig. 12 yields a velocity of $2.0 \mathrm{~km}-\mathrm{sec}^{-1}$ This reflects the low initial slope shown in the Fig. 12 insert. Beyond 1-kbar axial stress the curve is much steeper, and yields a velocity of $4.6 \mathrm{~km}-\mathrm{sec}^{-1}$ for the 


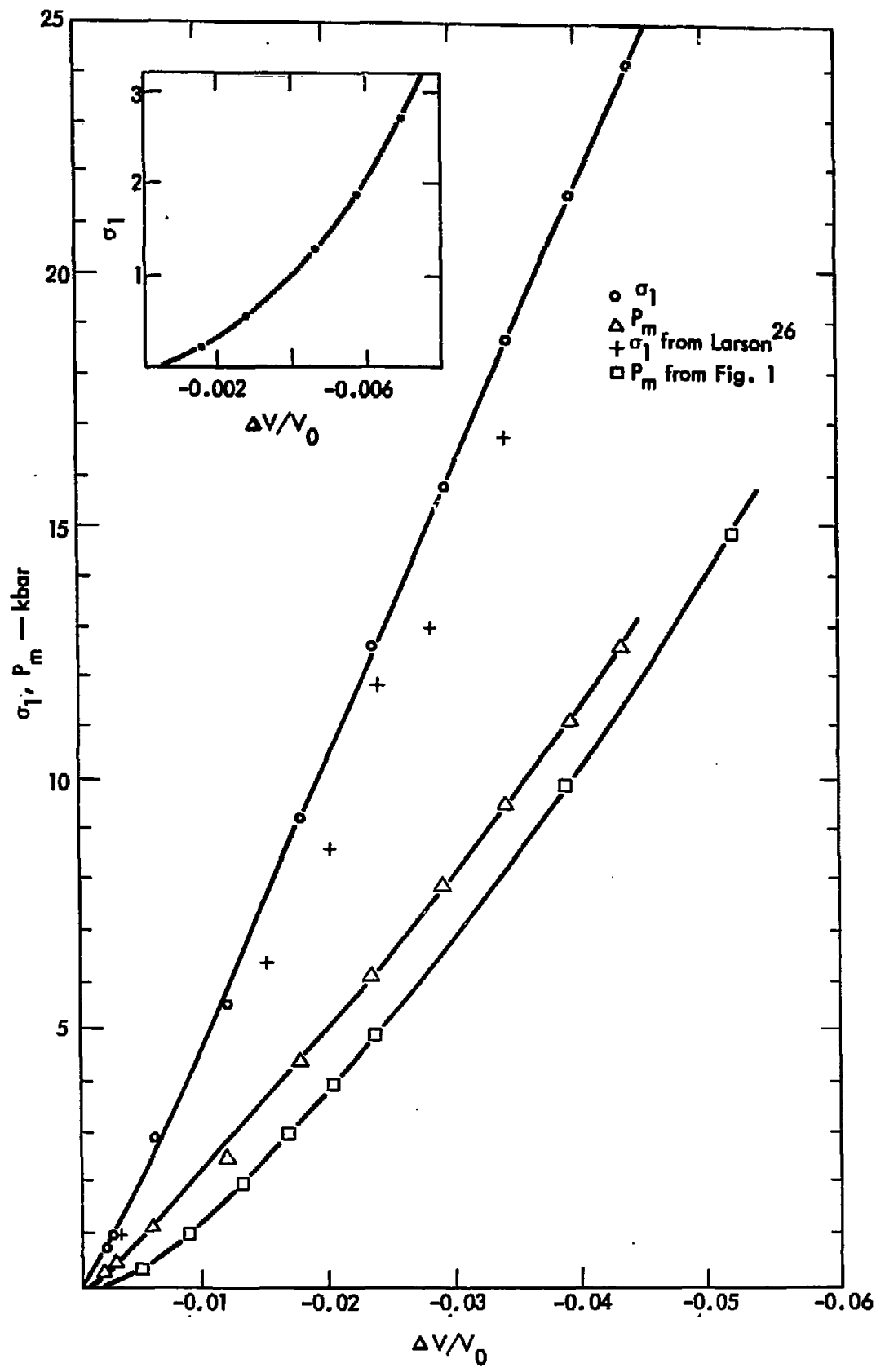

Fig. 12. Axial stress $\left(\sigma_{1}\right)$ and mean pressure $\left(P_{m}\right)$ as a function of volume strain for loading in uniasial strain. Shock-wave data obtained by Larson ${ }^{21}$ are shown for comparison. 
propagation of an elastic wave. This is the first material in which we have been able to observe such a steepening in a slope at pressures below $1 \mathrm{kbar}$ in a uniaxial strain test. The observed behavior at low stresses in the uniaxial stress tests and the behavior of cracks suggests that the effert may have been masked in the grantes by the relatively low strains due to compression of sracks. We observe no $c$ iscontinuity in the $\sigma_{1}$ versus $\Delta V / Y_{0}$ loajing curve attributable to pore collapse, as observed in more porous sandstones. 10 The low porosity of this sandstone apparently precludes this.

\section{Discussion}

Comparison of the hydrostatic pressure volume curve with the mear pressurevolume relation obtained in uniaxial strain (Fig. 12) reveals that the uniaxial sirain data show less compression than the hydrostatic data at corresponding mean pressures. Inspection of the uniaxial atress data in Figs. 6 and 9 shows that this loading path is also above the hydrostat. Granites load along the hydrostat to the highest stress attained in untaxial strain and to the onset of dilatancy in uniaxial stress. ${ }^{17}$ Other sandstones ${ }^{10}$ load along the hydrostat until they either dilate or undergo compaction due to collapse of their pore space. The disagreement between the hydrostat and mean pressurevolume curves in nonhydrostatic loading is probably due to cracks. In the uniaxial strain test, the maximum principal stress is always significantly greater (increases faster) than the confining pressure, causing those cracks oriented parallel to the principal applied stress to remain open. However, when the rock is compressed hydrostatically the cracks close without regard to orientation. This behavior has not been observed in the uniaxiai strain loading paths in granites, and is probably the result of the much smaller girains. 19
For granitic rocks, the computed volume strains have an uncertainty which approaches the theoretical difference (0.001 in strain) in the pressure-volume curves.

The data in Fig. 12 support the above argument. At pressures ahove 1 kbar, the off and the hydrostat is about 0.004 in strain. If one considers a three-dimensional array of homogeneously distributed and oriented cracks, on the average only onethird will close when a uniaxial stress is applied. Examination of the data in Fig. 12 shows that the compression at low pressures before the knee in the uriaxial strain test is about 0.0015 , or about one-third to one-fourth the total before the knee in the hydrostat $(0.005)$. Of course, this analysis is an oversimpliflcation. In reality cracks will exhibit a range of aspect ratios, external stresses will be transmitted internally through the rock matrix in a complex fashion, and perfect agreement to the above model should not be expected. The theoretical treatments of Walsh ${ }^{21}$ and Walsh and Brace $^{27}$ predict such an effect on cracks at low stresseg.

The initial loading data in Fig. 11 and 12 yield an effective shear modulus of 
56 kbar anc an effective bulk modulus of 43 kbar. These are in good agreement with the values obtained on uniaxial stress loading at 1 bar. However, the bulk modulus is higher than that calculated from hydrostatic loading, presumably due to the effect just analyzed. At axial stress values above 1 kbar, the effective shear modulus becomes $219 \mathrm{kbar}$ and remains relatively constant with increasing stress. The effective bulk modulua above the knee in Fig. 11 is $268 \mathrm{kbar}$ and increases with increasing stress. These values agree very well with those from the initial loading in uniaxial stress at $1-\mathrm{kb}$ ar confining pressure.

On unloading, the mean pressure-volume strain daty in Fig. 12 do not show any detectable departure from the loading values. However, the data in Fig. 11 show an initial stiffening in shear response on unloading. This is believed to result from friction on surfaces which slide on loading and become temporarily locked when stresses are relaxed.

In summary, we have determined the mechanical properties of samples from a block of dry Nugget sandstone $\left(\rho_{0}=2.56 \mathrm{~g}=\mathrm{cm}^{-3}\right.$ ) both at atmospheric and under high confining pressures. The initial loading moduli are found to be strongly influenced by an inelastic phenomenon at stress levels below 1 kbar. This phenomenon is believed to represent the closing of cracks with low-aspect ratios. At confining pressures of $1 \mathrm{kbar}$ and above, theze cracks appear to be closed and the rock exhibits a much stiffer response to both shear and simple compressive stresses. No evidence of an Irreversible collapse of pore space is found to pressures of $30 \mathrm{kbar}$. The rock dilates before failure in the same mo- :er as granitic rocks. Failure in uniaxial stress is by brittle fracture to the highest confining pressures atiained (7.0 kbar).

\section{Acknowledgments}

During the course of this work we have had outstanding technical assistance from E. Joslyn, E. Lilley, H. Louis, and

B. Washington. We are grateful to
D. Larson for providing preliminary high strain rate data and for discussion of these and other pertinent results on sandstones. 


\section{References}

1. W. F. Brace and D. K. Riley, Intern. J. Rock Mech. Min. Sci. 9, 271 (1972).

2. F. J. Pettijohn, Sedimentary Rocks (Harper and Bros., New York, 1957) 2nd ed.

3. F. J. Pettijohn, P. E. Potter, and R. Siever, Sand and Sandstone (SpringerVerlag, New York, 1972).

4. D. R. Stephens, E. M. Lilley, and H. Louis, Intern. J. Rock Mech. Min. Sci. 7, 257 (1970).

5. J. Handin and R. V. Hager, Jr., Am. Assoc. Petrol. Geol. Bull. 41, 1 (1957).

6. A. A. Giardini, J. F. Lakner, D. R. Stephens, and H. D. Stromberg, J. Geophys. Res. 73, 1305 (1968).

7. R. N. Schock, H. C. Heard, and D. R. Stephens, J. Geophys. Res. 78, 5922 (1973).

8. R. N. Schock and A. G. Duba, J. Appl. Phys. 43, 2204 (1972).

9. H. C. Heard, "The Inflience of Environment on the Inelastic Behavior of Rocks," Proc. Engr. Nucl. Expl. (Am. Nucl. Soc., 1970), vol. 1, p. 127.

10. K.N. Schock, H.C. Heard, and D.R. Stephens, Comparison of the Mechanical Properties of Graywacke Sandstones from Several Gas Stimulation Sites, Lawrence Livermore Laboratory, Rept. UCRL-51261 (1972).

11. R. N. Schock, H.C. Heard, and D. R. Stephens, High-Pressure Mechanical Properties of Rocks from Wagon Wheel No. 1, Pinedale, Wyoming, Lawrence Livermore Laboratory, Rept. UCRL-50963 (1970).

12. M. Friedman and J. M. Logan, J. Geophys. Res. 75, 387 (1970).

13. R.N. Schock, H. Louis, and E. M. Lilley, The Determination of Acoustic Velocities and Dynamic Elastic Moduli in Rocks under Pressure, Lawrence Livermore Laboratory, Rept. UCRL-50750 (1969).

14. R. K. Cook, J. Acoust. Soc, Am. 29, 445 (1957).

15. F. Birch, J. Geophys. Res. 65, 1083 (1960).

16. R. N. Schock, H.C. Heard, and D. R. Stephens, Mechanical Properties of Rocks from the Rio Blanco Stimulation Experiment, Lawrence Livermore Laboratory, Rept. UCRL-51260 (1972).

17. R. N. Schock, "Dynamic Elastic Moduli of Rocks Under Pressure," in Proc. Engr. Nucl. Expl. (Am. Nucl. Soc., 1970) vol. 1, p. 110.

18. G. Simmons and W.F. Brace, J. Geophys. Res. 70, 5649 (1965).

19. R.N. Schock and A.G. Duba, Expl. Mech. 13, 43 (1973).

20. R. N. Schock, A.E. Abey, H. C. Heard, and H. Louis, Mechanical Properties of Granite from the Taourirt Tan Afella Massif, Algeria, Lawrence Livermore Laboratory, Rept. UCRL-51296 (1972).

21. J. B. Walsh, J. Geophys, Res. 70, 5249 (1965)

22. W. F. Brace, B.W. Paulding, and C. Scholz, J. Geophys. Res. 71, 3939 (1966).

23. C. Scholz, J. Geophys. Res. 73, 1417 (1968). 
24. R. N. Schock and H. C. Heard, Static Mechanical Properties and Shock-Loading Response in Granite, Lawrence Livermore Laboratory, Preprint UCRL-74708 (1973).

25. T. J. Ahrens and V.G. Gregson, Jr., J. Geophys. Res. 69, 4839 (1964).

26. D. B. Larson, personal communication.

27. J. B. Walsh and W. F. Brace, Intern. J. Rock Mech. and Mining Sci. 9, 7 (1972). 